\title{
Determinants of Mobile Money Remittance in East Africa
}

\author{
Oscar Correia ${ }^{1}$, Philip Ngare ${ }^{2}$, Durvine Sindiga ${ }^{1}$ and Desmond Otwoma ${ }^{1}$ \\ The Catholic University of Eastern Africa \\ ${ }^{2}$ The University of Nairobi
}

\begin{abstract}
Globally, remittances represent an important flow of international financial resources. In the East African trading bloc, the dynamic population movements between countries has led to widespread distribution of population across the region. This has driven the demand for migrant workers to send money home. Mobile money has seen a rapid growth within individual East African countries with Kenya, Tanzania and Uganda topping the global volume of mobile money transfers. One would expect the Mobile Money Remittance within the East African region to follow a similar trend being an extension of the local service. However, its uptake across borders appears to be slow. This study seeks to identify the consumer determinants that affect the uptake of the service. The study is based on the Technology Acceptance Model which gathers insight through the lens of usefulness, ease of use, perceived cost, availability of alternatives and risk perception. Once the data was collected a Cronbach alpha was applied to ensure their reliability for the purpose. The research showed that Perceived Usefulness and Perceived Ease of Use are key drivers for the mobile international remittance. This could be expected given the mobile money background of the users. In addition, the Perceived Cost of International Mobile Remittance is a key driver of behavioral intent. There was little evidence to show that Attractiveness of Alternatives and Perceived risk actually discouraged users from using International Mobile Remittances.
\end{abstract}

Key words: Mobile Money Remittance in East Africa, Technology Acceptance Model, Empirical study, Cronbach alpha.

\section{Introduction}

The advent of Mobile phones has transformed the financial industry and access to services. The GSMA reports that mobile money services are now available to 1.9 billion people with 270 live services (as of December 2015) (GSMA - The Mobile Economy 2016).

Mobile money services have transformed local money transfer methods in Sub-Saharan Africa, with potential to improve the efficiency of international remittances. The World Bank reports that remittances costs globally are approximately $7.42 \%$ of the amount transferred. While South Asia is the cheapest receiving country at $5.41 \%$, Sub Saharan Africa remains as one of the highest of 9.52\%. (World Bank - Remittance Prices World Sept 2016). The following graph shows time-series of the costs of remittance based on where the money is being sent. The figures were calculated using the World Banks SmaRT methodology (World Bank June 2016)

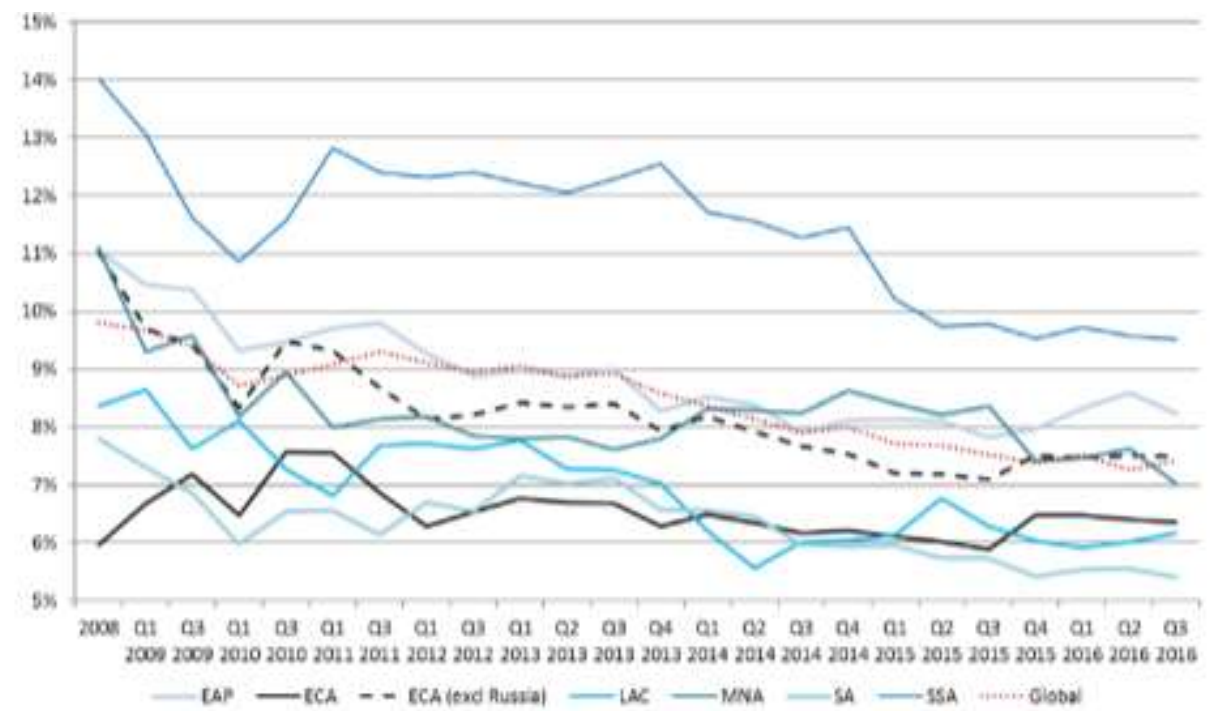

Figure 1 Average total costs by region of the world (World Bank, Remittance Prices Worldwide (2016)) 
The below graphs show the price differential between the different types of Remittance Service Providers (RSP) viz. banks, Post Offices and MTOs.

Figure 10 Total averages over time by RSP type

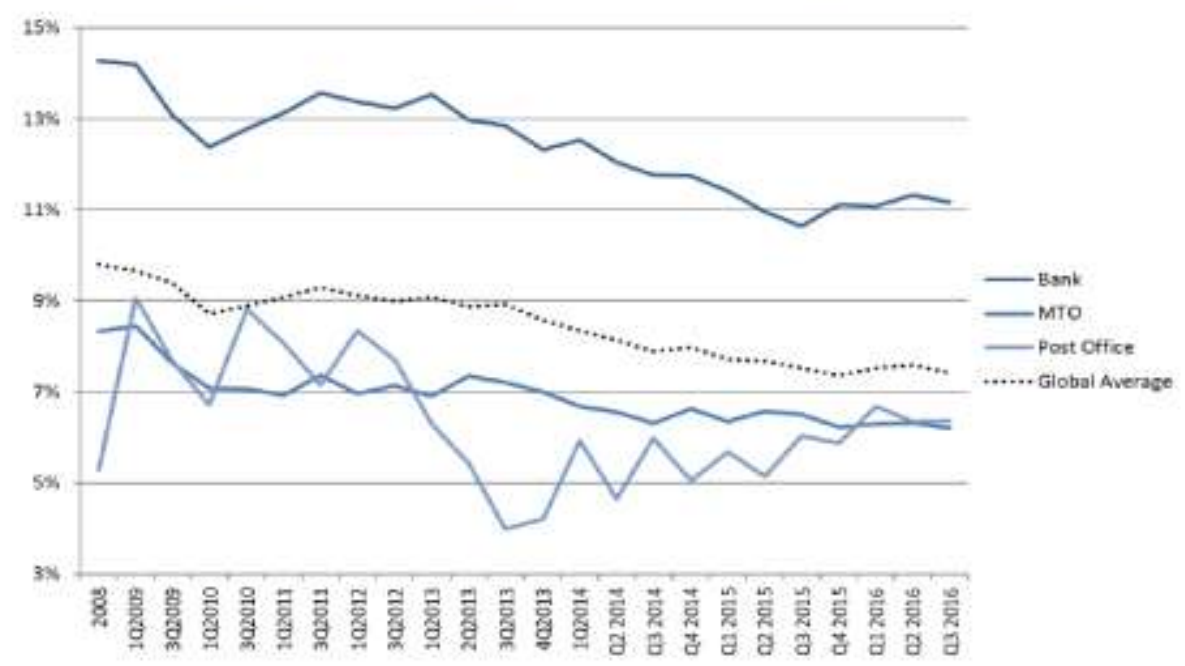

Figure 2 Total averages over time by RSP type (World Bank, Remittance Prices Worldwide (2016))

The same World Bank report describes the split between the different types of remittance methods. It is important to note how Pre-Paid card services and Mobile services are among the cheaper modes of international remittance.

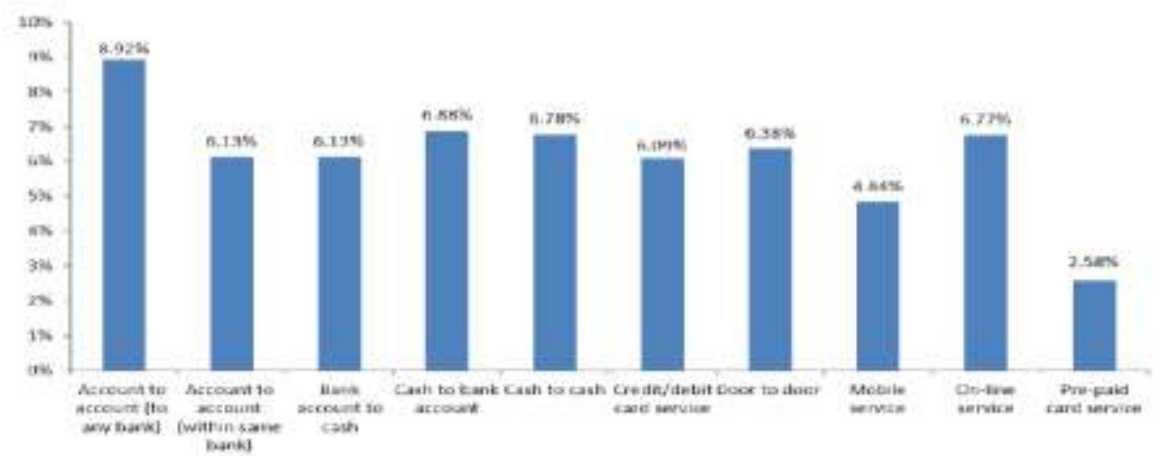

Figure 3 Average cost by Service type in Q3 2016 (World Bank, Remittance Prices Worldwide (2016))

In 2015, the GSMA SOTIR report (GSMA 2015) noted that cross-border remittances increased by $51.8 \%$ and represented the fastest growing of all mobile money services.

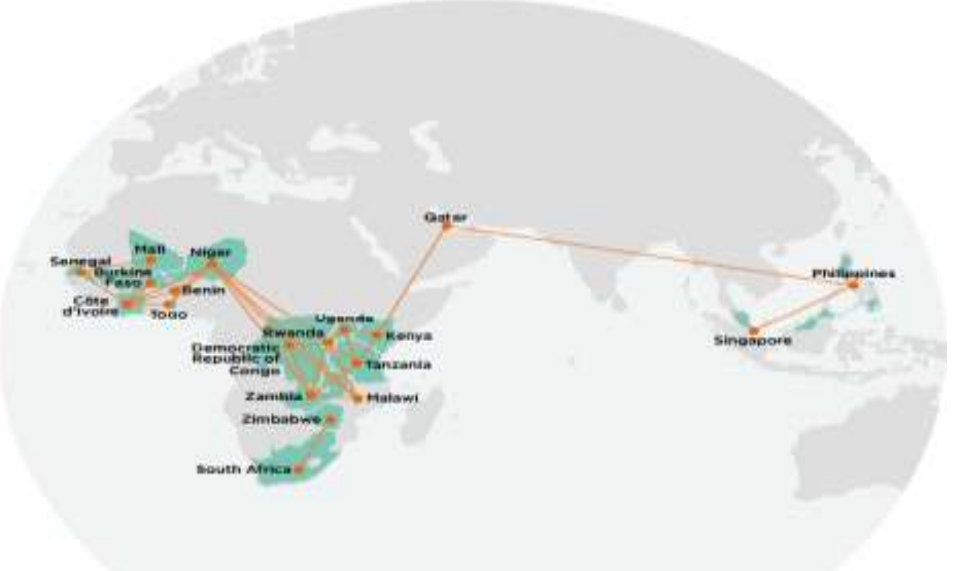

Figure 4 Live corridors for cross-border mobile money remittances initiatives (December 2015) (GSMA 2015) Nevertheless, while remittances represent a very small component of the mobile money ecosystem $(0.1 \%$ by volume and $1 \%$ by value) it demonstrates a 10 -fold multiplier of transaction versus volume. 


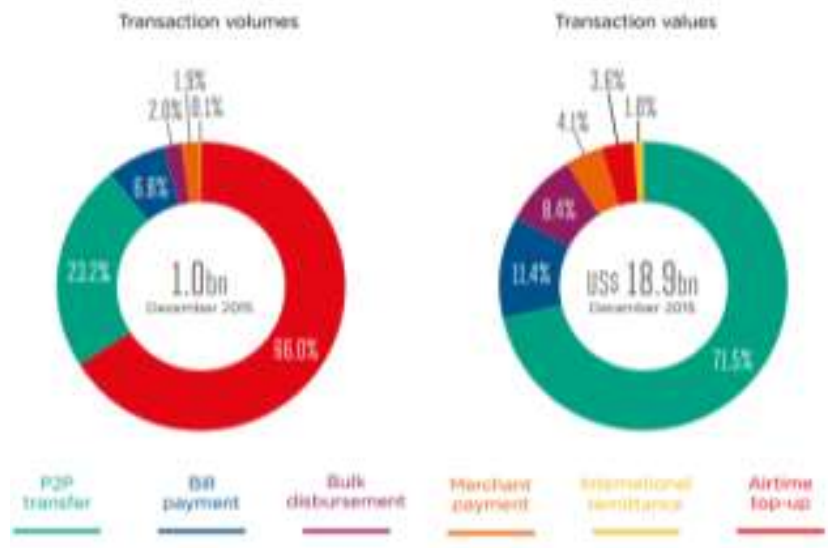

Figure 5 Global Product mix by volume and value (December 2015) (GSMA 2015)

Global remittance flows exceeded \$580 billion in 2014 and the World Bank Group estimates that SubSaharan Africa alone will receive $\$ 34$ billion in 2016. In addition, the global financial institutions have identified the significance of the contribution of remittances to local development and have committed to reducing the current rate to less than 5\%. (G8 - Responsible Leadership for a Sustainable Future). This will lead to greater volumes transacted via mobile phones with cheaper costs for consumers, greater capital flows to developing countries, and increased support of infrastructure that can help combat corruption and counter the financing of terrorism. (Richard 2012)

Geographic branch and ATM penetration is lowest in developing markets while mobile subscription growth rates are at the highest level in these markets. (Daly 2010). Specialist remittance service providers such as Western Union, with over 350,000 points of presence, targeted to the relevant segmentation, address this issue to a degree. However, the high costs associated with maintaining this type of distribution network create another significant entry barrier for consumers. The World Bank estimates that reducing remittance commission charges by $2-5 \%$ could increase the flow of formal remittances by $50-70 \%$, boosting local economies. (World Bank 2016)

In her introduction to the GSMA report, Francesca Brown (GSMA 2015) describes how the UK - as part of its Sustainable Development Goals is targeting to reduce the average cost of remittances to less than $3 \%$ of the amount being transferred by 2030 while ensuring that individual remittance corridors charge no higher than $5 \%$ by the same time. This requires the need to ensure interoperability of mobile networks, proportionate anti-money laundering standards and cross-border money flows. Mobile money is one of the most exciting innovations in financial services, with more than 400 million registered customer accounts across more than 90 countries. (Farooq 2016). Mobile money services are available in 85 percent of countries where the number of people with an account at a financial institution is less than 20 percent. The results show that mobile money is driving a price revolution in international remittances. It is doing this by increasing competition, leveraging existing networks and infrastructure, and capturing smaller remittance values than traditional players.

While sending remittance via mobile money is cheaper than most other methods, it is commonly used to send small amounts (\$82 in June 2015) compared to typical remittance values (\$500). Money Transfer Operators have dropped prices in markets where they are in competition with mobile money operators indicative of the need for supportive regulatory environments to support the fledgling industry. By extension, this has increased the level of financial inclusion in the areas where it has been deployed.

GSMA highlights (GSMA 2015) that mobile money services (covering 170 million mobile money accounts) offered customers the ability to send money across 45 country corridors (mostly between African markets where formal remittance channels are limited). The report highlights how $\$ 5.2$ billion (1.2\% of the $\$ 431.6$ billion remitted to developing countries) was sent across 45 corridors. The perceived benefits are increased convenience and security. As remittances come directly to the phone they can then be used to pay bills, make transfers, or simply store value, without having to travel to an agent. On the sending side, customers can easily check the cost of initiating transfers from a mobile phone, allowing them to send funds when the exchange rate is most appropriate.

One in seven Africans (120 million) (World Bank 2016) receives remittances from friends and family abroad, as much as a third of total GDP in some African markets. Although 'North-South' remittance flows are the largest, one in three remittances are sent from within Africa. (Scharwatt, 2015).

Daly (2010) claims that figures from the Philippines published in a World Bank and GSMA paper, documented a churn reduction from $3 \%$ to $0.5 \%$ for Mobile Money customers. He also identifies three use cases 
for mobile money: Mobile to mobile, Mobile to cash and Cash to mobile. The mobile to mobile use case is purely an electronic remittance which originates from the send consumer's mWallet and terminates in a receive consumer's mWallet, in a different market. This presents the lowest cost to the consumer as the distribution costs are removed on either end. The mobile to cash use case originates from a consumer's mWallet and terminates at a cash-out point in a different market while Cash to Mobile involves the sender sending cash to the recipient's mobile wallet.

Remittances are an important source of income for many low and middle-income households in developing countries. Second, remittances provide the hard currency needed for importing scarce inputs that are not available domestically and additional savings for economic development (Ratha, Taylor and Quibria et al). Le (2011) develops a model which examines the motivation of sending remittances (typically due to altruistic or business motivations) and shows that remittances not only compensate the recipients for unfavorable economic conditions but also serve as an important flow of capital as well as monetary rewards for investment managerial efforts.

These scenarios illustrate the importance of the following design principles for mobile remittances (Singh, 2009): First, design for everybody, including users who lack print and financial literacy. This approach is particularly important when the recipient has little financial literacy and numeracy. Universal design (Preiser, 2001) must be a starting point of the design of mobile remittances, particularly if women are to become banked and financially included because of this technology. Second, given a choice of cash-in and cash-out points to make the mobile a preferred channel. The greater choice will widen the options so that the characteristics of the channel meet the needs of the senders and recipients for different kinds of remittances. Third, use the ability of mobile remittances to target multiple recipients. This will enable the remittance to empower women, without directly confronting traditional patterns of money management and control. Fourth, ensure the privacy of the information of money transfers, keeping in mind the boundaries of information sharing within the family. Issues of fit, privacy and trust are particularly important as they differ across cultures. Fifth, engender trust in the transaction, the provider and the agent by clarifying ways of gaining redress. Quinn (2005) finds evidence, using selectivity corrected remittance and savings equations to show that developing access to better savings and investment mechanisms for household's results in increase remittance inflows from household members.

Driffield (2013) observes that both FDI and migrant remittances have a positive impact on growth in developing countries. In addition, this is attenuated by a better institutional environment, in that countries that protect investors and maintain a high level of law and order will experience enhanced growth. Lindley (2009) raises issues of wider significance relating to recent debates on Somali migrants' remittances, informal economies and conflict and how it can become an opportunity for adaptive commercial actors using social ties to navigate the dangers of civil war. Apecu and Abadalla (2014) have recorded that East Africa has witnessed a rapid rise in money transfer services through leveraging mobile phone applications and use.

\section{Theoretical Background}

User acceptance has been identified as the crucial success factor (Zmijewska, Lawrence \& Steeke, 2004). It is based on a belief that the most important component in mobile payments systems - and by extension, international remittance - is the user (Bradford, 2003).

Kreyer et al. (2002) use the example of credit cards to support the key role of the customer in the process of acceptance of a new payment method. Credit cards spread in Europe due to strong consumer demand, even though merchants were forced to pay 3-5\% fees. Amberg et al (2003) similarly sees the user acceptance as a critical success factor for mobile services. If eventually it is the user who decides whether a new system is accepted, user adoption behavior deserves thorough analysis and discussion.

Dahlberg et al (2003) has identified that the application areas of mobile payment solutions have broadened to include among other things vending, ticketing, purchase of mobile telephony services, mobile commerce (ring-tones, logos, news, mobile games...), electronic banking, peer to peer fund transfers, purchase from the Internet, and purchase of services/goods from service providers and shops. Mobile payment solutions cover all main financial payment methods; cash, direct debit, credit card, and payment against service bill. The idea of providing international remittance through mobile phones attracts customers owing to its convenience. Moreover, the services can be widely used only if they imply a reduction in costs as compared to traditional banking or remittance tools (Darbellay \& Weber, 2010).

Several previous studies on mobile payments have focused on using the Technology Acceptance Model (TAM) (Schierz et al. 2010; Kim et al. 2010; Yan and Pan 2014; Shaw 2014) based on the traditional model proposed by Davis (Davis, 1989; Davis et al., 1989) as well as other models such as the Innovation Diffusion Theory (Rogers 1962, 1983, 1995; Rogers \& Shoemaker 1971; Lu et al. 2011; Li et al. 2014) and Unified Theory of Acceptance and Use of Technology (UTAUT) (Wang and Yi 2012; Slade et al. 2014) to examine mpayment user behavior. 
While there has been a lot of attention to mobile payment systems, little focus has been applied to cross-border transfers. While cross-border transfers would at first sight seem similar to ordinary mobile payments, differences arise from the fact that the sending and receiving currencies are often different. In addition, owing to regulatory boundaries rules and regulations may differ between countries thus increasing the perceived risk of consumers sending money. Lastly, knowledge and complexity of transfer fees and redress mechanisms are often vaguely understood by end-users thus contributing to their overall resistance to use the service. The objective of this study is to extend the current literature by investigating the facilitators and inhibitors of mobile remittance systems.

\section{Review of different technology acceptance models}

The different models can be grouped into three major groups: Innovations Diffusion Theory (IDT) (Rogers 1995; Moore \& Benbasat 1991; Plouffe, Hulland \& Vandenbosch 2001); Intention Based Theories specifically the Technology Acceptance Model (TAM) (Davis 1989; Davis, Bagozzi \& Warshaw 1989; Venkatesh \& Davis 1996, 2000) and other theories such as Social Cognitive Theory (SCT) (Compeau, D.R. \& Higgins 1995; Compeau, D.R., Higgins \& Huff 1999).

While a compressive comparison of user acceptance models is beyond the scope of this paper, TAM was chosen since it is easy to apply across different research settings and compares favorably in parsimonious compatibility (Han 2003). This provides grounds to compare it with other mobile payment studies. In addition, while TAM does not consider Social Norms, Davis (Davis, Bagozzi and Warshaw (1989)) explained that Social Norm scales have a very poor psychometric standpoint, and may not exert any influence on Behavioural Intent.

Darlberg et al (2003) identifies perceived usefulness and perceived ease of use jointly affects a person's attitude toward using the system and consequently the behavioral intention to use the system, which then leads to actual systems use. The measures of perceived usefulness include overall usefulness, time savings, increased job performance, productivity increase, effectiveness and performance increase. Correspondingly, measures for the perceived ease of use include flexibility of use, clarity, ease of use, ease of understanding, ease of learning and ease of control. (Darlberg, Mallat and Oorni, 2003).

Many authors used the TAM and various extended versions of TAM to research consumer acceptance of mobile banking applications (Chung and Kwon, 2009; Gu, Lee and Suh, 2009; Kleijnen, et al., 2004; Luarn and Lin, 2005; Yu and Fang, 2009). Davis et al. (1989) observes that, compared to theory reasoned action (TRA), TAM constitutes a simpler and more parsimonious model because the belief variables are mainly context-independent (PU- Perceived Usefulness; and PEOU- Perceived Ease of Use), whereas, in the case of the TRA, it is necessary to develop a series of leading beliefs specific to the context. TAM is frequently used in studies of mobile service adoption because of its ease of applicability and simplicity (Chong et al., 2012, Venkatesh and Davis, 2000, Zampou et al., 2012, Zhou, 2013).

TAM has been criticized for not fully capturing why mobile phone users do not adopt mobile commerce, which in the present case is mobile banking (Lee and Jun, 2007). Tobbin (2010) suggested that PEOU and PU were most significant determinants of Behavioral Intention (BI) to use mobile money. TAM however did not focus on other variables that could impact the ease of use, usefulness and user acceptance and thus did not fully explain behavioral intention towards mobile money (Mukherjee, 2015). Researchers have noted that the TAM omits variables that may be important predictors of IT/IS usage (Mathieson, et al., 2001). Lee and Jun (2007) argued that TAM should also be able to analyze factors affecting the adoption intentions beyond perceptions of usefulness, ease of use and social norms. TAM is also limited in people's willingness and determination to adopt technology for a specific purpose is sufficient for adoption (Luarn and Lin, 2007).

\section{Theoretical Framework}

For our study, we will use the valence framework as a guiding principle. This framework looks at perceived risk and perceived benefit as drivers for consumer decision making (Lu et al 2011). This may help to breakdown the factors influencing the choice mobile remittance technologies. Nevertheless, this framework does not define the precise dimensions of the model and so for this we shall use the Technology Acceptance Model.

The Technology Acceptance Model (TAM) builds on the theory of reasoned action (TRA) (Fishbein and Ajzen, 1975). TAM looks at the uptake of new technology as explained by the behavioural intention (BI) that is guided by an individual's attitude towards using the technology which in turn is influenced by two psychological components; perceived usefulness (PU) and perceived ease of use (PEOU).

PEOU was defined as the extent to which the system was perceived to be free of effort, and PU was defined as the extent to which the system was perceived to enhance the job performance of an individual (Davis, 1989).

Behavioural intention was defined as a cognitive decision making process to perform a behavior or action (Das and Pal 2011). Attitude refers to a prospective user's favorable or unfavorable feelings toward using 
a specific technology or system. Behavioral intention is the direct determinant of a prospective user's technology or system usage, a necessary precursor to the actual behavior (Fishbein and Ajzen, 1975).

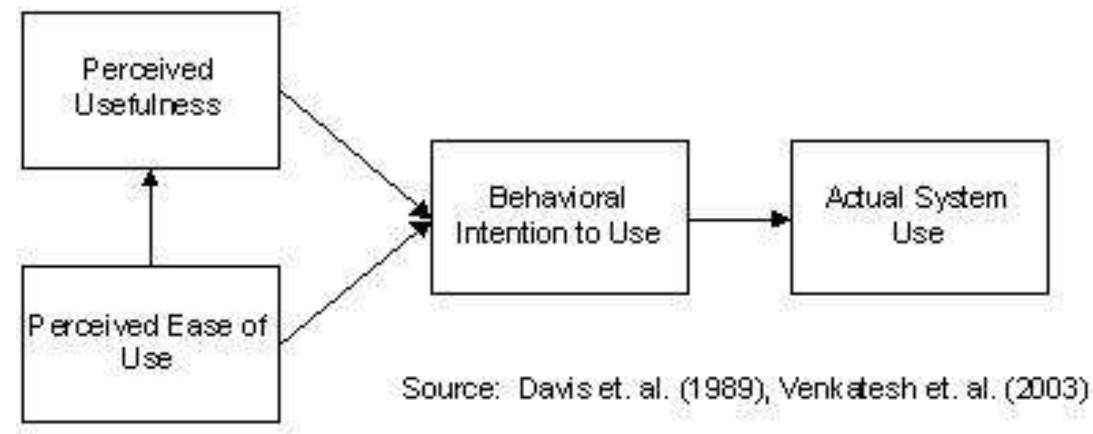

Figure 6 TAM Model

\section{Perceived Risk (PR)}

Perceived risk (PR) is commonly thought of as felt uncertainty regarding possible negative consequences of using a product or service. Perceived risk was identified as a barrier to the usage of any system and was hypothesized to impact the intention to use mobile money negatively (Mallat, 2007). It has formally been defined as a combination of uncertainty plus seriousness of outcome involved" (Bauer, 1967) and 'the expectation of losses associated with purchase and acts as an inhibitor to purchase behavior" (Peter and Ryan, 1976). It is also referred to as the perception of potential negative outcomes that might occur if the system was used or adopted (Tobbin, 2011).

One factor that research has identified as a critical determinant of consumers' willingness to buy a new product or brand is the perceived risk associated with the purchase. (Grewal et.al, 2006). Previous research suggests that a new product's price and the way advertised information is communicated affect consumers' perceptions of the performance risk of a new product (Shimp and Bearden 1982). Most of scholars claimed that consumers' perceived risk is a kind of a multi-dimensional construct (Lee, 2009). Six components or types of perceived risk have been identified: financial, performance, social, physical, privacy, and time-loss (Jacoby and Kaplan, 1972; Kaplan et al., 1974; Roselius, 1971). However, the dimensions of perceived risk may vary by product (or service) class (Featherman and Pavlou, 2003).

In the case of mobile remittance, the risk is two-fold: whether there is risk in storing the money in the electronic wallet and the risk if the recipient will receive the money. Given that this study is conducted in East Africa where there is already a huge uptake of mobile money, the risk of storage of the money in the electronic wallet is a significant barrier. However, the possibility of the recipient receiving the funds is a source of considerable risk.

\section{Perceived Financial Cost (PFC)}

Perceived Financial cost was a matter of concern in adopting mobile financial services (Das and Pal, 2011). Besides abundant discussions regarding consumer satisfaction, Voss, Parasuraman, and Grewal (1998) suggested that the perceived price decision has an impact on consumers' satisfaction in service industries. Perception about cost was especially important in the developing countries, where consumers might find the service useful, but the cost might act as a prohibitive factor (Mukherjee, 2015). Perceived financial cost was listed as an important predictor of m-payments usage (Zmijewska et al., 2004).

The costs of adopting mobile financial services include the registration fees for accessing the network, a service or usage charge per transaction, cost of a new handset incase the old handset is not able to support the interface needed to use mobile money service and other possible non-monetary costs including health hazards etc. The paper focuses on perceived financial cost only as a determinant of mobile remittance usage intention.

\section{Attractiveness of Alternatives (AOA)}

Attractiveness of alternatives means the reputation, image and service quality of the replacing carrier, which are expected to be superior or more suitable than those of the existing carrier. Attractiveness of alternatives are more strongly associated with customer satisfaction. (Ping, 1999). Attractiveness of alternatives is intimately linked to service differentiation. If a company offers differentiated services that are difficult for a competitor to match or to provide with equivalents, or if few alternative competitors exist in the market, customers tend to remain with the existing company (Bendapudi \& Berry, 1997). Depending on the quality of competing alternatives, the customer perceives a benefit in changing the provider (Oliver 1997). The more attractive the alternatives are, the higher the perceived benefits when switching (Jones et al. 2000). Therefore, 
consumers are likely to switch once they perceive alternative offerings as being superior with respect to the costbenefit ratio (Kalyanaram and Little 1994; Sivakumar and Raj 1997). (Mallat, 2007) explored consumer adoption of mobile payments in a qualitative study where it was compared with other traditional modes of payments like credit/debit cards or cash. It is generally expected that credible alternatives would negatively impact the intention to adopt mobile money therefore AOA was used to refer to perception of how effective the alternatives were in comparison with such a service (Cheong, Park and Hwang).Demand from the rural population were the key drivers for adoption of mobile financial services (Das and Pal, 2011).

Remittance is not a new service and has existed for as long as peoples have crossed borders for work and migration. Indeed, banks and Money Transfer Operators dominate the market place. Consequently, the use of mobile remittances is equally threatened by competition from these alternatives. This study seeks to investigate how this perception affects the consumer choices in the use of mobile remittance.

\section{Research Model and Hypothesis Development}

The research model used is shown in the figure below:

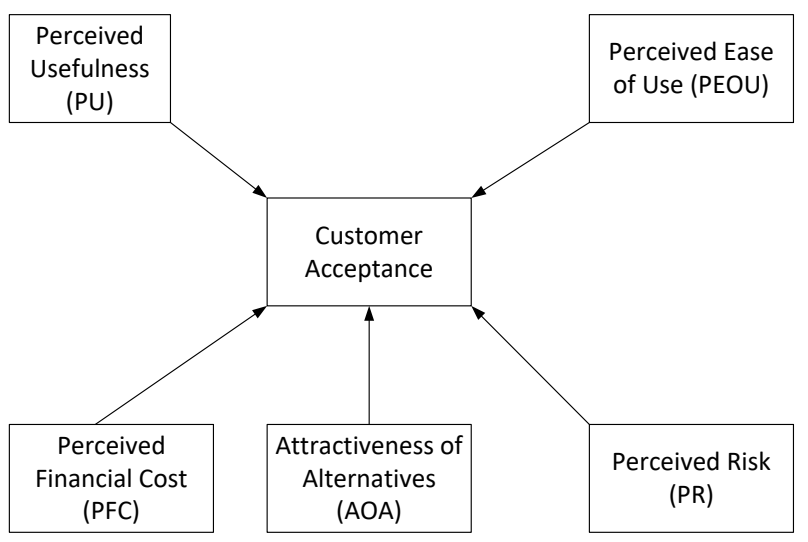

Figure 7 TAM Model Proposed

There was need to understand comprehensively the behavioural intention to mobile money for international money remittances. PU and PEOU were considered as important determinants for the behavioural intended use of mobile money remittances.

To better understand the specific elements covered under each determinant, convenience and speed of making transactions were considered in the case of PU. Thus, we hypothesize:

H1: Perceived usefulness has a positive effect on international mobile money remittance.

Ease of payment procedure, knowledge of remittance corridors and understanding of the interaction with the system (e.g. the system response) were taken as an integral part of the payment system and were considered for PEUO. Thus, we hypothesize:

H2: Perceived ease of use has a positive effect on international mobile money remittance.

In the market, there exists alternative methods of making money remittances. The customer's choice to switch to the mobile money remittances will be influenced by factors like the cost and risk of using alternatives.

H3: Attractiveness of alternatives negatively impacts the behavioural intention to use international mobile money.

Risk creates a significant barrier to the adoption and acceptance of mobile money remittances. Key elements considered here include chance of making errors, risk of unauthorized use and risk of losing money while using the system.

H4: Perceived risk negatively impacts the behavioural intention to use international mobile money.

Cost is an important determinant of intention to use mobile financial services in a global context (Das and Pal, 2011). As mentioned in various World Bank studies (World Bank 2016), the cost of sending money to SubSaharan Africa and within Sub-Saharan African countries is among the highest in the world.

H5: Perceived financial cost positively impacts the behavioural intention to use international mobile money.

Many researchers focus on determining whether the various factors affect the behavioural intention of customers in the acceptance and use of mobile money remittances. No specific research has compared the different elements of the TAM model to determine the most influencing factor.

\section{Research Methodology}

The study seeks to analyze the different perceptions users of international money transfer have towards Mobile Money as an alternative for remittance. This study can be identified as ex post facto research given that 
the respondents were studied presumably after they had made their choice on which medium of money transfer they adapted.

Customer acceptance of mobile money remittance is the dependent variable that is influenced by various independent variables including; perceived ease of use, perceived usefulness, perceived financial costs, attractiveness of alternatives and perceived Risk. The study was carried out in Nairobi which is the financial hub for Kenya, East Africa and has widespread use of mobile money.

Purposive Sampling technique was used to target individuals who use international money remittance services. In this type of sampling, the respondents for the sample are selected deliberately by the researcher; his choice concerning the items remains supreme (Kathari, 2004).

An online survey was used to collect the respondents. Questionnaire was piloted before distribution and in order to ensure validity, triangulation was applied within the tool with the use of Cronbach's alpha to establish the reliability of the questions.

The research design was based on individual users of mobile money services. The survey included both those who used mobile money to send internationally as well as those who had not sent money using mobile money. However, the respondents needed to have known about sending and receiving money and also needed to have done it. The survey was shared online and was also physically administered to users to capture the data. A Likert scale was used for most the questions where the answers were based on a five-point scale where the lowest value was the last likely and the highest value being the most likely. The values were then aggregated together to form a single value for each variable under consideration. Appropriate weightings were applied to each value and then used to calculate the final value. The customer acceptance was determined by how often the customer used the service.

\section{Sampling and Data Collection}

The actual online survey was conducted using Google Forms. The physical administration was done by using a printed version of the questionnaire. Once the physical questionnaires were collected, they were entered into the online survey tool to ensure consistency of the data capture.

The survey was circulated to over 500 respondents using e-mail, personal conversations, email, social media and various chat forums. It was also shared as a physical form and participants were asked to fill in the questionnaire in the presence of the person administering the questionnaire.

The target audience were Kenyans (or people familiar) with the Kenya mobile remittance market. The survey was conducted both among local and international users but all in the context of sending money to and from Kenya. The data was collected through the period of November and December 2016.

\section{Data Analysis}

The number of responses received were 101 which represents a $20 \%$ response rate. This is in line with the literature regarding the use of online surveys. Out of the 101 questionnaires responded to there were 55 males who responded and 46 females who responded. This reflects a gender balance in terms of respondents as well as service / potential service usage. The average age of the respondents was about 34 years.

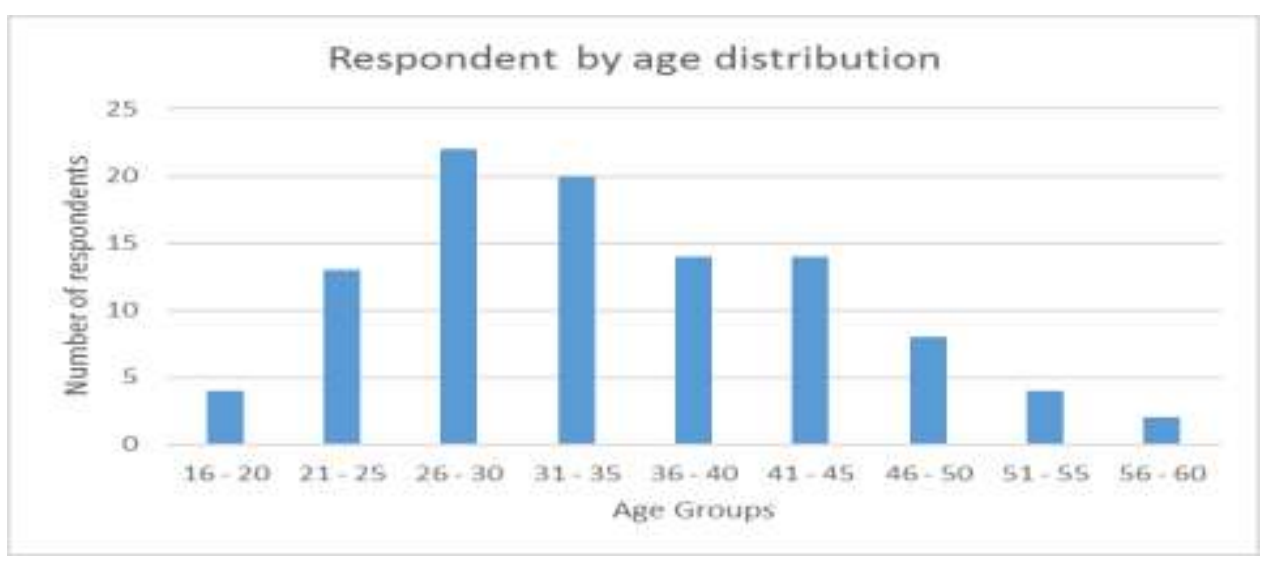

Figure 8 Respondent by Age

$80 \%$ of the respondents were based in Kenya. Manyof the users were quite experienced with mobile money services, as can be seen in the graph below: 


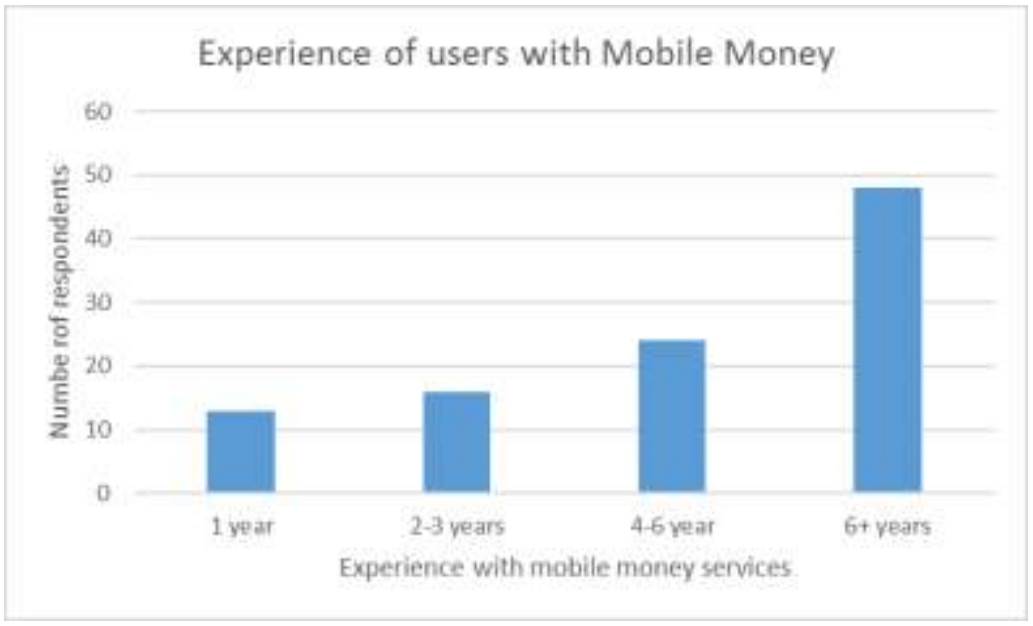

Figure 9 User experience of mobile money

While all the respondents had heard of mobile remittance $50 \%$ of the respondents had not sent or received international remittance. In this scenario, we measured the behavioural intention to send and receive mobile international remittance.

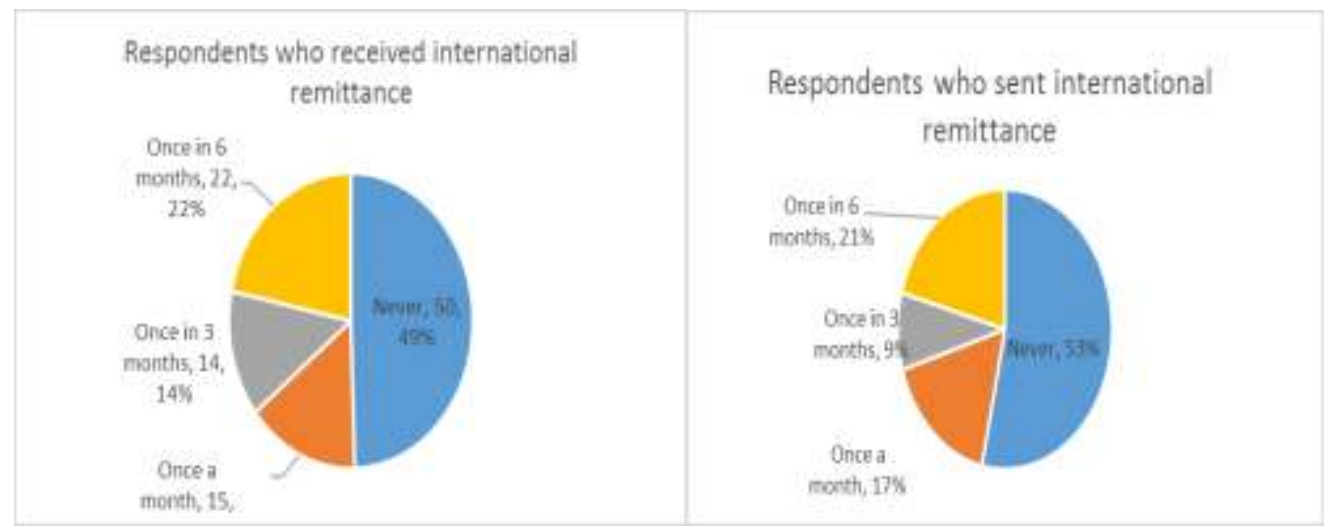

Figure 10 Respondents frequency of using international remittances

The below pie charts show the distribution of the countries to which money is sent from Kenya and received from other counties.

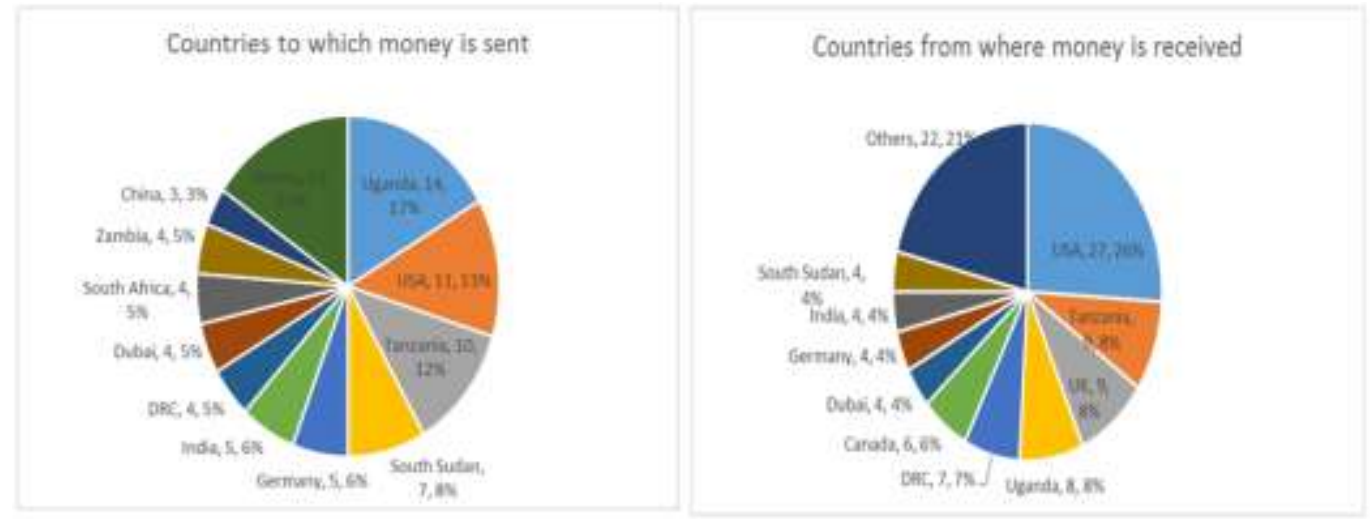

Figure 11 Respondents distribution of countries sent to and received from

Excel and SPSS were used for the data analysis. The data was downloaded from Google Forms with prepopulated data. However, some recodification was required to apply the appropriate weighting to the questions as well as to adjust for the direction of the question.

Once the data was collected a Cronbach alpha was applied to ensure their reliability for the purpose. The Cronbach alpha values are shown below: 
Table 1 Cronbach Alpha by research constructs

\begin{tabular}{|l|l|}
\hline Item & Cronbach's Alpha \\
\hline Behavorial Intention & 0.7051 \\
\hline Perceived Usefulness & 0.6576 \\
\hline Perceived Ease of Use & 0.8494 \\
\hline Perceived Financial Cost & 0.6944 \\
\hline Attractiveness of Alternatives & 0.6817 \\
\hline Perceived Risk & 0.7161 \\
\hline
\end{tabular}

The overall Cronbach alpha was 0.795 . This shows that the measurement (through the questionnaire) of the theoretical constructs met the minimum reliability requirements needed for the research. Cronbach alpha requirements above 0.7 provide a strong indication of validity for the use of measuring instruments while measurements between 0.6 and 0.7 are indications of moderately strong reliability. As can be seen from the above data, 3 of the values (BI, PU, and PFC) are above the 0.7 threshold and 2 of the values (PFC and AOA) are very near it indicative of a reasonably strong reliability. One measure is only moderately strong (PU).

The data was then analyzed using multiple regression in SPSS. The results are as shown in the table below:

Table 2 Model Summary

\begin{tabular}{|c|c|c|c|c|c|}
\hline \multicolumn{6}{|c|}{ Model Summary } \\
\hline Model 1 & $\mathbf{R}$ & R Square & Adjusted R square & Std Error of the Estimate & \\
\hline 1 & 0.952 & 0.907 & 0.902 & \begin{tabular}{|c|}
0.83733 \\
\end{tabular} & \\
\hline \multicolumn{6}{|c|}{ ANOVA } \\
\hline Model & Sum of Squres & df & Mean Square & $\mathbf{F}$ & Sig \\
\hline Regression & 650.206 & 5 & 130.041 & 185.476 & 0.000 \\
\hline Residual & 66.606 & 95 & 0.701 & & \\
\hline Total & 716.812 & 100 & & & \\
\hline \multicolumn{6}{|c|}{ Coefficients } \\
\hline \multirow[t]{2}{*}{ Model 1} & \multicolumn{2}{|c|}{ Unstandardized Coeffeicients } & $\begin{array}{l}\text { standardized } \\
\text { Coeffeicients }\end{array}$ & & \\
\hline & B & Std Error & Beta & $\mathbf{T}$ & Sig \\
\hline Constant & 0.504 & 0.463 & & 1.088 & 0.279 \\
\hline PU & 1.172 & 0.116 & 0.412 & 10.088 & 0.000 \\
\hline PEOU & 1.145 & 0.137 & 0.373 & 8.385 & 0.000 \\
\hline PFC & 0.546 & 0.086 & 0.226 & 6.352 & 0.000 \\
\hline $\mathrm{AOA}$ & 0.502 & 0.093 & 0.173 & 5.416 & 0.000 \\
\hline PR & 0.468 & 0.099 & 0.175 & 4.709 & 0.000 \\
\hline
\end{tabular}

\section{Discussion}

By applying the beta co-efficient in the proposed model we can see model takes the shape as seen in the Figure below.

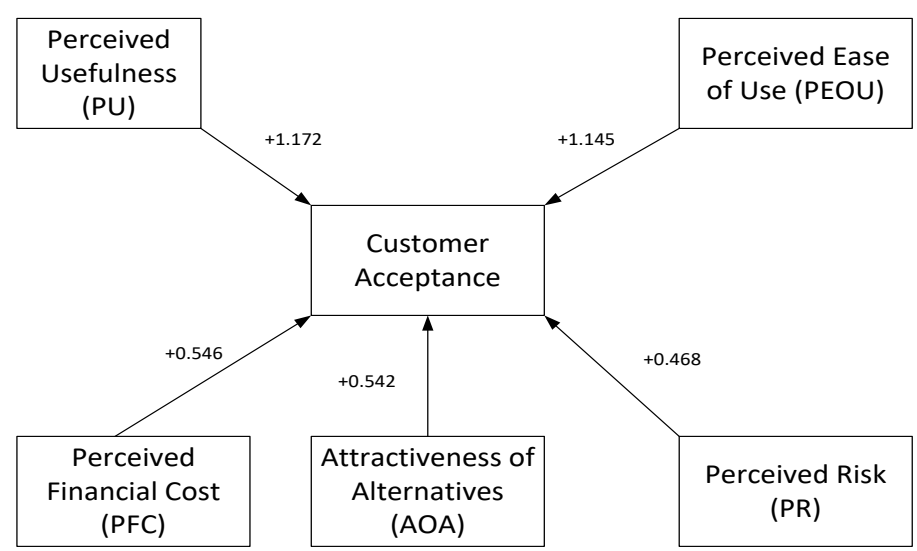

Figure 12 Updated model with beta coefficients

From the above model, we can see that the Perceived Usefulness and Perceived Ease of Use are significant contributors to the use of International Remittance. This is probably driven by already existing user experience of Mobile Money - given its huge success in Kenya. This allows us to reject the null hypothesis that Perceived Usefulness and Perceived Ease of Use of the service has no impact on the intention to the use the 
service. Hence this supports our H1: Perceived usefulness has a positive effect on international mobile money remittance and H2: Perceived ease of use has a positive effect on international mobile money remittance.

With respect to the Attractiveness of Alternatives hypothesis, it is possible that the lack of alternatives would drive the uptake of the service. Hence we would reject the null hypothesis that Attractiveness of Alternatives has no impact on behavioral intent. Hence we would reject our hypothesisH3: Attractiveness of alternatives negatively impacts the behavioural intention to use international mobile money, and recommend further research into this area.

In a similar fashion, we would reject the null hypothesis that perceived risk negatively impacts the behavioral intent of using mobile remittance and we would need to reject our hypothesis that H4: Perceived risk negatively impacts the behavioural intention to use international mobile money as it would appear that existing users of mobile money services already have a certain level of trust in mobile money platforms and expect them to be safe.

Lastly, we would reject the null hypothesis that perceived cost has no impact on international mobile remittance and hence accept our proposed hypothesis H5: Perceived financial cost positively impacts the behavioural intention to use international mobile money.

\section{Improvements}

This research can be further enhanced by purposive sampling in which actual mobile money service providers allow researchers to access their customers to answer the same questionnaire. This would allow for a greater number of samples to be obtained as well as data from more relevant customers. In addition, incentives could be provided for the participants to encourage their response to the survey. This will need user consent as well as approval from the National Research Body. The research can also be further improved by dividing sampling populations into net receivers and net senders and determine their behavioral patterns based on these criteria. Lastly, the use of transaction values in future research can give grounds for comparisons with the amounts (and thus the perceived risk) of funds transferred by traditional methods.

\section{Conclusion And Directions For Future Research}

As can be seen from the previous discussions there are numerous avenues to extend this research. Further research is possible particularly along specific corridors (e.g. Kenya - Uganda or Kenya - Tanzania). Each corridor will have its own mitigating factors in terms of demographics as well as facilitating conditions which provide further variables for analysis. Other areas of study include the possibilities of Kenyans abroad paying for local services using mobile money. While this does not fit snugly in the domain of personal remittances it still reflects inflows of money into the economy. Lastly, but not least, there is the possibility of studying the underground or shadow money transfer money mechanisms where agents setup shop in foreign countries and appear to be operating locally.

\section{References}

[1]. Apecu, J., Sewankambo, I.K \& Abdalla, Y.A (2014). Mobile money services provision in East Africa: the Ugandan experience in Lim, A.H and De Meester, B. (eds) WTO Domestic Regulation and Services Trade: Putting Principles to practice. Cambridge: Cambridge University Press, $201-220$.

[2]. Bauer, R. (1967). Consumer behavior as risk taking. In: Cox, D. (Ed.), Risk Taking and Information Handling in Consumer Behavior. Harvard University Press, Cambridge, MA.

[3]. Cheong, J.H. \& Park, M.C. (2005). Mobile Internet acceptance in Korea. Internet Research, 15(2).

[4]. Chong, A.Y.L, Chan, F.T.S \& Oooi, K.B. (2012), Predicting consumer decisions to adopt mobile commerce: Cross country empirical examinations between China and Malaysia. Decision support systems, 53(1), 125 -140.

[5]. Compeau, D.R., Higgins, C.A. (1995). Computer self-efficacy: Development of a measure and initial test, MIS Quarterly. $189-211$.

[6]. Compeau, D.R., Higgins, C.A. (1995). Social cognitive theory and individual reactions to computing technology: A longitudinal study. MIS Quarterly. 145-158.

[7]. Dahlberg, T., Mallat, N. \& Oorni, A., 2003. Consumer Acceptance of Mobile Payment Solutions - Ease of Use, Usefulness and Trust. The Second International Conference on Mobile Business. Vienna, Austria, 2003.

[8]. Daly, N. (May 2010) International Remittance Service Providers, An overview of mobile International Remittance Service Provider service offerings. GSMA

[9]. Dass, R. \& Pal, S. (2011). Exploring the Factors Affecting The Adoption Of Mobile Financial Services Among The Rural UnderBanked. European Conference on Information Systems, ECIS 2011 Proceedings, 246.

[10]. Davis, F. (1989) Perceived Usefulness, Perceived Ease of Use, and User Acceptance of Information Technology, MIS Quarterly, 9, 319-340.

[11]. Davis, F., Bagozzi, R. \&Warshaw, P (1989) User Acceptance of User Technology: A Comparison of Two Theoretical Models, Management Science, 35, 982-1002.

[12]. Driffield, N. \& Jones, C. (2013) Impact of FDI, ODA and Migrant Remittances on Economic Growth in Developing Countries: A Systems Approach. European Journal of Development Research 25, 173-196. doi:10.1057/ejdr.2013.1

[13]. Farooq S., Naghavi, N., \& Scharwatt C. (2016) GSMA Driving a price revolution Mobile money in international remittances, GSMA, October

[14]. Featherman, M.S \& Pavlou, A.P. (2003). Predicting e-services adoption: A perceived risk facets perspective. Paper presented at the Eighth Americas Conference on Information Systems. 
[15]. Fishbein, M., \& Ajzen, I. (1975). Belief, attitude, intention and behavior: An introduction to theory and research. MA: Addis onWesley.

[16]. Grewal, D.D.R, Palmatier, R. \& Evans, K. (2006). Factors Influencing the effectiveness of relationship marketing: A meta-analysis. Journal of Marketing, 70 (4), 136 - 153.

[17]. GSMA. (2016). The Mobile Economy, 2016. Retrieved from http://www.gsma.com/mobileeconomy/. Retrieved 2016, December

[18]. World Bank (2016). Remittance Prices Worldwide Issue No. 19, September 2016. Retrieved from http://remittance.worldbank.org. Retrieved 2016, December.

[19]. GSMA. (2015). State of the Industry Report Mobile Money. Retrieved from http://www.gsma.com/mobilefordevelopment/programmes/mobile-money/industry-data-and-insights/sotir Retrieved 2016, November.

[20]. G8. (2009). Responsible Leadership for Futurehttp://www.g8italia2009.it/static/G8 Allegato/G8 Declaration 080709 final,0.pdf. Retrieved 2016, November.

[21]. Han, S 2003, Individual adoption of information systems in organizations: a literature review of technology acceptance model, TUCS Technical Report 540, TUCS.

[22]. Jacoby, J.,\& Kaplan, L.B. (1972). The components of perceived risk. Proceedings of the Third Annual Conference, Ann Arbour, MI, Association for Consumer Research.

[23]. Jones, Michael. A., David L. Mothersbaugh, and Sharon E. Beatty (2000), "Switching Barriers and Repurchase Intentions in Services," Journal of Retailing, 76 (2), 259-74.

[24]. Kalyanaram, Gurumurthy and John D. C. Little (1994), “An Empirical Analysis of Latitude of Price Acceptance in Consumer Package Goods," Journal of Consumer Research, 21 (3), 408-19.

[25]. Kim, C., Mirusmonov, M., \& Lee, I. (2010). An empirical examination of factors influencing the intention to use mobile payment. Computers in Human Behavior, 26(3), 310-322.

[26]. Le, T. (2011). Remittances for Economic Development: the Investment Perspective, School of Economics, The University of Queensland

[27]. Lee, K.C. \& Chung, N. (2009). Understanding factors affecting trust in and satisfaction with mobile banking in Korea: A modified DeLone and McLean's model perspective. Interacting with Computers, 21(5-6), 385-392.

[28]. Lee, T.M., \& Jun, J.K (2007). The role of contextual marketing offer in mobile commerce acceptance: comparison between mobile commerce users and non-users. International Journal of Mobile Communications, 5(3), 339-356.

[29]. Lindley, A. (2009). Between 'Dirty Money' and Development Capital': Somali Money Transfer Infrastructure under Global Scrutiny. African Affairs, Vol. 108, No. 433 (Oct., 2009), pp. 519-539. Oxford University Press on behalf of The Royal African Society.

[30]. Lu, Y., Yang, S., Chau, P. Y., \& Cao, Y. (2011). Dynamics between the trust transfer process and intention to use mobile payment services: a cross environment perspective. Information \& Management, 48(8), 393-403.

[31]. Li, J., Liu, J.-L., \& Ji, H.-Y. (2014). Empirical study of influence factors of adaption intention of mobile payment based on TAM model in China. International Journal of U \& E-Service, Science \& Technology, 7(1), 119-132.

[32]. Luarn, P., \& Lin, H.H. (2005). Towards an understanding of the behavioral intention to use mobile banking. Computers in Human Behavior, 21, 873-891.

[33]. Mathieson, K., Peacock, E., \& Chin, W.W. (2001), Extending the technology acceptance model: The influence of perceived user resources. Database for Advances in Information Systems, 32(3), 86-112.

[34]. Mallat, N. (2007). Exploring consumer adoption of mobile payments - A qualitative study, The Journal of Strategic Information Systems, 16(4), $413-432$.

[35]. Moore, G. C., \& Benbasat, I. (1991). Development of an instrument to measure the perceptions of adopting an information technology innovation. Information Systems Research 2(3), 192-222.

[36]. Pavlou, P. (2001). Integrating trust in electronic commerce with the technology acceptance model: model development and validation. AMCIS Proceedings, Boston, MA.

[37]. Peter, J. \& Ryan, M. (1976). An investigation of perceived risk at the brand level. Journal of Marketing Research, 13, 184-188.

[38]. Ping, R. (1996). Latent variable interaction and quadratic effect estimation: a two-step technique using structural equation analysis. The Psychological Bulletin 119, 166.

[39]. Preiser, W.F.E., Ostroff, E. (eds.): Universal Design Handbook. McGraw-Hill Professional,

[40]. New York (2001)

[41]. Plouffe, C.R. Vandenbosch, M., Hulland, J. (2001). Intermediating technologies and multi-group adoption: A comparison of consumer and merchant adoption intentions toward a new electronic payment system. Journal of Product Innovation Management $18(2), 65-81$

[42]. Quibria M.G. (1997) International Migration, Remittances, and Income Distribution in the Source Country: A Synthesis, Bulletin of Economic Research, 49(1), (1997), 29-34.

[43]. Quinn, M. (2005). Remittances, Savings, and Relative Rates of Return. The Journal of Developing Areas, Vol. 38, No. 2 (Spring, 2005), pp. 1-23

[44]. Ratha, D. (2003) An important and stable source of external development finance. Global Development Finance, World Bank; Washington D.C.

[45]. Richard, C. (2012). Mobile Remittance and Mobile Remittances And Dodd-Frank: Reviewing The Effects Of The CFPB Regulations, Volume XII - Spring

[46]. Roselius, T. (1971) Consumer rankings of risk reduction methods. Journal of Marketing, 1971, 35, 56-61.

[47]. Rogers, E. M. (1962). Diffusion of Innovations, 1st Edition, The Free Press, New York.

[48]. Rogers, E. M. (1983). Diffusion of innovations, 3rd Edition, The Free Press, New York.

[49]. Rogers, E. M. (1983). 1995, Diffusion of Innovations, 4th Edition, The Free Press, New York, NY.

[50]. Rogers, E.M, Shoemaker, F.F. (1971). Communication of Innovations: a cross-culture approach, 2nd Edition, Free Press, New York.

[51]. Scharwatt, C., \& Williamson, C. (2015) Mobile money crosses borders: New remittance models in West Africa. GSMA.

[52]. Schierz, P. G., Schilke, O., \& Wirtz, B. W. (2010). Understanding consumer acceptance of mobile payment services: an empirical analysis. Electronic Commerce Research and Applications, 9(3), 209-216

[53]. Schierz, P. G., Schilke, O., \& Wirtz, B. W. (2010). Understanding consumer acceptance of mobile payment services: an empirical analysis. Electronic Commerce Research and Applications, 9(3), 209-216.

[54]. Singh, S. (2009). Mobile Remittances: Design for Financial Inclusion. N. Aykin (Ed.): Internationalization, Design, LNCS 5623, pp. $515-524$ 
[55]. Sivakumar, K. and S. P. Raj (1997), "Quality Tier Competition: How Price Change Influences Brand Choice and Category Choice," Journal of Marketing, 61 (3), 71-85.

[56]. Shaw, N. (2014). The mediating influence of trust in the adoption of the mobile wallet. Journal of Retailing and Consumer Services, 21(4), 449-459.

[57]. Shera, A., Meyer, D., (2013). Remittances and their impact on Economic Growth. Social and Management Sciences, 21/1 (2013) 3 19

[58]. Shimp, T.A., \& Bearden, W.O, (1982), Warranty and Other Extrinsic Cue Effects on Consumers' Risk Perceptions," Journal of Consumer Research, 9 (6), 38-46.

[59]. Slade, E., Williams, M., Dwivedi, Y., \& Piercy, N. (2014). Exploring consumer adoption of proximity mobile payments. Journal of Strategic Marketing, 23(3), 209-223

[60]. Taylor, J.E. (1999) The New Economics of Labor Migration and the Role of Remittances in the Migration Process, International Migration, 37(1), 63-68.

[61]. Tobbin, P \& Kuwornu, J.K., (2011). Adoption of mobile money transfer technology: structural equation modeling approach! European Journal of Business Management, 3(7), 29-77.

[62]. Venkatesh, V., Davis, F. (2000). A theoretical extension of the technology acceptance model: four longitudinal field studies. Management Science 46 (2), 186-204.

[63]. Wang, Y.-S., Wu, S.-C., Lin, H.-H., Wang, Y.-M., \& He, T.-R. (2012). Determinants of user adoption of web 'Automatic Teller Machines': an integrated model of 'Transaction Cost Theory' and 'Innovation Diffusion Theory'. The Service Industries Journal, 32(9), 1505-1525.

[64]. Weber, R.H \& Darbellay, A. (2010). Legal issues in mobile banking, Journal of Banking Regulation. 11 (2) 129

[65]. Yan, H., \& Yang, Z. (2015). Examining mobile payment user adoption from the perspective of trust. International Journal of u-and e-Service, Science and Technology, 8(1), 117-130.

[66]. Zmijewska, A, Lawrence, E. \& Steele, R. (2004a). Towards a successful global payment system in mobile commerce. Paper presented at the IADIS International E-commerce, Lisbon, Portugal

[67]. World Bank. (2016). Getting SmaRT about remittance price monitoring. https://remittanceprices.worldbank.org/sites/default/files/smart methodology.pdf 